\title{
Environmental Explorations: Integrating Project-Based Learning and Civic Engagement Through an Afterschool Program
}

\author{
Rachel Farmer \\ University of Kentucky \\ NaKayla Greene \\ University of Kentucky \\ Kristen H. Perry \\ University of Kentucky \\ Cindy Jong \\ University of Kentucky
}

This study examined the Community Super Investigators Club, through which we aimed to apply mathematics and literacy skills by using project-based learning (PBL) to investigate elementary students' interest in learning how to improve the environment for animals. PBL is a teaching method used to improve critical thinking skills around a project that is based on students' questions. The study used a mixed-method design to examine the following research questions: How do students engage in PBL on topics relevant to their community in an afterschool club? How can critical math and literacy skills be integrated with community engagement? How did the experience in the club influence students' beliefs about math and literacy? During Community Super Investigators Club, participating second- and third-grade students chose the topic of improving the environment for animals. Students learned about the following topics: reducing waste and recycling, the amount of trash produced around the world, using recyclable items to build bird feeders, and how trash in the oceans affects animals. Researchers interviewed and surveyed students. Students reported that they could make a positive impact in their community by not littering, reusing materials to minimize waste, and turning off the water while brushing their teeth. As a final project, students selected an outlet or person (e.g. newspaper, governor) to write a postcard to voice their concerns about the environment by including at least one fact and one proposed solution. Implications for practice are integrated into the findings and discussion.

\section{Introduction}

There are myriad pedagogical approaches for engaging students, but one prevailing approach is project-based learning (PBL). In PBL, students formulate questions to investigate topics that are of interest and relevant to their own lives, while a teacher facilitates the students' project. The goal of the investigation is to gain a better understanding of the topic through viewing the issue from diverse perspectives and exploring solutions for it (Basche, Genareo, Leshem, Kissell, \& Pauley, 2016). Krajcik and Blumenfeld (2006) claimed that PBL has five key features: (a) a driving question; (b) students' exploration of the question by applying knowledge of a discipline; (c) students, teachers, and community members' collaboration to solve the problem, supporting students by sharing experiences; (d) engagement in an authentic inquiry process; and (e) students creating a project or tangible product to address their question. PBL is thought to be successful in motivating students to learn and develop crucial skills for future betterment of the world (Bell, 2010). 
Formal classroom settings can be monotonous for students, making it difficult for them to engage with subjects being taught in the classroom. The lack of motivation for learning in formal settings, which focus on acquiring narrow skills that do not provide meaning to the students, has driven the development of informal settings (Rahm, Martel-Reny, \& Moore, 2005; Turner, Gutiérrez, SimicMuller, \& Diez-Palomar, 2009). Informal settings, such as afterschool and community programs, can be more appealing to youth because the activities involved are not focused on completing worksheets. The students use mathematics and science as tools during their activities instead of being lectured about the subjects (Rahm et al. 2005). According to Turner et al. (2009),

Students who feel that their out of school experiences are valued and integrated with their formal schooling have greater potential to see school as relevant and are better positioned to see mathematics, in particular, as a powerful tool in their lives. (p. 139)

Therefore, programs in informal settings have the potential for students to connect meaning in what they have learned in school and apply it to their lives.

In a study of afterschool and community science programs, Rahm et al. (2005) found that participants have diverse motives for joining the programs in contrast to being required to participate in formal settings. The motives tended to aim to satisfy intrinsic needs, compared to formal settings where motives typically satisfy extrinsic needs. The results of the study also suggested that participants in the programs gained a stronger interest and deeper understanding of how science plays a role in their daily lives. One participant, Rosine, had no interest in science before the program. After the program, she was upset she was not able to go more in depth in her research and was confident she wanted a future career in the field of science (Rahm et al., 2005). Without the program, she might not have viewed science as more than just a class taught in school. Learning out of school allows students to understand how they can connect experiences outside of class with what they are learning in class (Turner et al., 2009). In this study, we investigated the following research questions:

Research Question 1: How do students engage in PBL on topics relevant to their community in an afterschool club?

Research Question 2: How can critical math and literacy skills be integrated with community engagement?

Research Question 3: How did the experience in the club influence students' beliefs about math and literacy?

\section{Project-Based Learning and Student Engagement}

By providing a clear purpose for students through connecting to their lives, PBL is one way to overcome the struggle of gaining students' attention (Genc, 2015) and to promote deeper learning (Bell, 2010). PBL is typically student driven, as students develop their own research questions and outline their own activities for the project (Bell, 2010). Thus, according to Powell, Cantrell, and Adams (2001), "students become engaged in writing, sharing, and discussing stories and information that have relevance in their everyday lives" (p. 775). The ability to connect with topics that are relevant to themselves and their communities is particularly helpful for students from minority backgrounds and underrepresented groups, whose nondominant perspectives and experiences tend to be less represented in classrooms (Turner et al., 2009).

PBL promotes motivation and engagement in a variety of ways. In more formal learning environments, students conduct projects at the end of a unit. In contrast, PBL allows students to engage in project work from the beginning-PBL is the unit, rather than being an add-on (Wilhelm $\&$ Confrey, 2005). Group work is a necessary component of PBL, promoting authentic discussions that help students to feel that their thoughts are important (Simic-Muller, Turner, \& Varley, 2009). 
In addition to motivation, PBL promotes deep learning. Wilhelm and Confrey (2005), for example, found that students' projects led to increased conceptual learning. In a study comparing students' experiences who learned science with a PBL curriculum and a standard science classroom, Basche et al. (2016) found that students involved in PBL were significantly less likely to want answers given to them by teachers than students in more standard classroom settings. Students in the PBL group enjoyed ownership in planning the project independently and finding solutions.

\section{Integration of Mathematics and Literacy}

Effective mathematics instruction should include real-life examples to demonstrate how mathematics is used in authentic situations without "predictable outcomes as textbook problems usually do" (Simic-Muller et al., 2009, p. 207). Similarly, scholars who promote authentic literacy instruction argue that students must read and write for real purposes and real audiences (Edelsky, 1991). By addressing real-life problems, PBL allows students to engage in both mathematics and literacy for authentic purposes. This authenticity fosters the development of important mathematics and literacy skills, and it also can foster more positive attitudes toward both subjects.

PBL promotes conceptual understanding and procedural skill in mathematics. In one project, for example, students used measurement and maps to calculate distances (Turner et al., 2009). Students can explore statistics in their research and make sense of the data presented. For example, Capraro (2017) brought a jar of quarters into her classroom and allowed students to generate questions such as "How many quarters in the jar are state quarters, and how many are not?" and, "What state are the quarters from and how many are from the 1800s? 1900s? 2000s?" Students split into separate groups to answer these questions, depending on their interests.

Through PBL, students develop literacy skills in reading, writing, and communication. Students read a variety of texts, including digital texts, to conduct research on specific topics of interest. They take written notes and share their findings in writing, often with audiences outside of the school (Powell et al., 2001). Students build oral communication skills by collaborating with peers, consulting with experts, and presenting their findings to various audiences (Christensen, 2015; Powell et al., 2001).

\section{Project-Based Learning and Civic Engagement}

Literacy and mathematics education have come to dominate the elementary curriculum, due to intense pressures on testing and other accountability measures. Yet, development of an informed and active citizenry is equally important (Hansen, Levesque, Valant, \& Quintero, 2018; KawashimaGinsberg, 2016; Westheimer, 2015). Schools should prepare learners to investigate, deliberate, and act upon important social issues (Kawashima-Ginsberg, 2016; Westheimer, 2015). High-quality civic education involves three components: knowledge, skills, and dispositions (e.g., "a sense of civic duty and concern for the welfare of others"; Hansen et al., 2018, p. 16). Over half the states in the United States have adopted the college, career, and civic life framework for social studies instruction, which advocates for an inquiry-based approach to helping students "to know, analyze, explain, and argue about interdisciplinary challenges in our social world" (National Council for the Social Studies, 2013). This framework thus aligns well with PBL approaches.

An excellent example of the ways in which PBL can be used to integrate critical mathematics and literacy instruction in service of civic education is captured in Powell et al.'s (2001) article, "Saving Black Mountain." The researchers documented a fourth-grade class in Kentucky which investigated issues related to strip-mining on the tallest mountain in that state. They reported that students "took a critical stance, talking with those in the region who benefitted from strip mining as well as those who opposed it" (p. 776). As the researchers reported, 
The fourth graders then began what can only be considered an all-out fight to save Black Mountain....They wrote to individuals to solicit funds to continue their campaign and subsequently collected thousands of dollars for the project. They alerted local newspapers and television stations and arranged for press conferences to talk about the mountain's future, and they even organized a "Hands Across the Mountain" rally with students from eastern Kentucky to raise public awareness. The...students also wrote to the governor and to various state representatives to make their opposition known. (p. 777)

Students also met with mining officials, submitted a proposal to the Department of Surface Reclamation and Enforcement, and gave a presentation to the state legislature. "Largely as a result of the students' efforts," the authors report, "a compromise agreement was reached... whereby 1,850 acres on Black Mountain would be saved from logging and strip mining” (p. 778).

\section{Method}

This mixed-methods research project took place during the afterschool program at a local public elementary school. Demographically, the school was 69\% White, 7\% Black, 16\% Hispanic, and 2\% Asian. Forty-three percent of students qualified for free and reduced lunch, 13\% were categorized as English learners, and $12 \%$ were in special education. For 7 consecutive weeks during the fall semester, we met with 10-19 second- and third-grade students weekly for $1 \mathrm{hr}$. Nineteen students (five boys and three girls in the third grade, six boys and five girls in the second grade) returned the parental consent forms to participate in the research portion of Community Super Investigators (CSI) Club. The researchers included two faculty members and two undergraduate students in a research fellowship at the University of Kentucky. We met weekly to plan and prepare activities, discuss literature, collect and interpret quantitative data, and analyze data from interviews.

During the first week of the CSI Club, we presented club participants with examples of different ways that children of similar ages impacted their communities. We discussed topics such as homeless animals, conscious consumers, the health and environmental effects of fast food, and minimizing wastes such as plastic, food, and trash. Students separated into small groups to brainstorm ideas about how they would like to contribute to improving the community. The final votes indicated interest in helping animals in the community, which evolved into exploring ways to improve the environment to indirectly affect animals. Based upon this decision, we planned a variety of weekly activities that integrated critical mathematics and critical literacy into thinking about community and the environment. Examples of these activities included making bird feeders from recycled materials, learning about the effects of mining from a university student outreach organization, researching the impact of plastics on the ocean, and writing postcards to various stakeholders to advocate for environmental action. Table 1 summarizes the various topics and activities that were implemented each week. 
Table 1. Weekly Topics and Activities

\begin{tabular}{|c|c|c|}
\hline Week & Lesson/Topic & Activity \\
\hline 1 & Introduction to CSI club & Brainstorm project ideas, vote on topic, preinterviews \\
\hline 2 & Research & $\begin{array}{c}\text { Ways to build a bird feeder out of recycled materials, planning of } \\
\text { design }\end{array}$ \\
\hline 3 & Bird feeder challenge & Implementation of bird feeder engineer design \\
\hline 4 & Trash week & Developing research questions about trash \\
\hline 5 & Guest speaker & $\begin{array}{c}\text { Mining activity, discussion of environmental damages such as } \\
\text { pollution and erosion }\end{array}$ \\
\hline 6 & Water focus & $\begin{array}{l}\text { Topic discussion related to Flint, MI, water crisis, impacts that } \\
\text { oceans and lakes have, and how we get clean water }\end{array}$ \\
\hline 7 & Ending to CSI club & $\begin{array}{l}\text { Final interviews/postsurveys and creating postcards for } \\
\text { stakeholders with power about conservation efforts in the region }\end{array}$ \\
\hline
\end{tabular}

Note. CSI = Community Super Investigators.

\section{Data Collection}

This study gathered a variety of data, including interviews, surveys, photographs, and student-made artifacts. We conducted interviews with participating children at the beginning of CSI Club and again at the end. Our interviews focused upon students' attitudes about reading and math, as well as their beliefs about whether children can impact their community. Interviews included survey questions asking students to rate how they felt about each topic based on four emojis ranging from very happy to very sad (Figure 1). Example questions included, "How do you feel when you use math to figure out how to do things at home or with your friends?" "How do you feel when you read an informational text at school (e.g., true facts about animals)?" and "How do you feel about kids helping to fix issues in their community?" After 7 weeks, we conducted follow-up interviews. These interviews again asked students to rate their attitudes toward reading, math, and community engagement, but additionally asked about their experiences in the CSI club and their attitudes toward the hands-on projects and community efforts. Throughout the club's implementation, we gathered student-generated artifacts such as journals, projects with recycled materials, postcards about conservation efforts, and posters on conservation awareness, as well as photographs of the students' projects and activities.

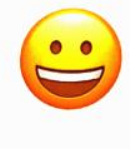

A

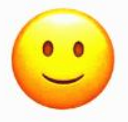

B

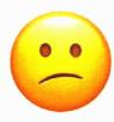

c

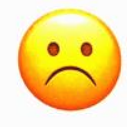

D

Figure 1. Emoji Scale Used for Student Survey Questions

\section{Data Analysis}

Our data analysis involved both quantitative and qualitative approaches. Students' attitude surveys were scored using a Likert-type scale according to whether they indicated very happy faces, slightly happy faces, slightly sad faces, and very sad faces, with $4=$ very happy and $1=$ very sad, because "very happy" was the most favorable response. We compared pre- and postscores to measure the 
students' improvement or decline in their attitudes toward math, literacy, and improving their community.

After transcribing the pre- and post-interviews, we organized interview data in a spreadsheet that allowed us to efficiently identify common answers and develop themes across students. We also created profiles for each participant for whom we had collected both pre- and postinterviews. Profiles included students' quantitative survey ratings, photographs of their participation, project artifacts related to the learning activities, and scans of their journals, which contained research questions and notes. Developing these profiles allowed us to gain a better understanding of students' knowledge, skills, and how they benefited from CSI Club, and how they might extend their learned experiences from the project activities.

\section{Results}

Findings from our study suggested that to engage students with integrated math and literacy topics, projects need to be student-driven and have meaningful connections, which are both key features of PBL. These findings corresponded to our first two research questions about how students engage in PBL on topics relevant to their community in an afterschool club and how critical math and literacy skills can be integrated with community engagement. Survey data also indicated that experiences in the club had a positive influence on students' attitudes toward math, literacy, and their community impact. This finding was related to our third research question about how the experience in the club influences students' beliefs about math and literacy. We present the findings according to our three main themes.

\section{Student-Driven Topics}

Our first two research questions were explored concurrently using the following approaches: emphasizing students' interests, integrating media and technology in the projects, providing journals for students to write plans and thoughts, presenting literature relevant to topics for students to read, inviting guest speakers to present to students, and composing tangible projects based on the topic.

Each of these approaches contributed to the investigation of our research questions in different ways.

The first and, arguably, most important step we took to incorporate students' intrinsic curiosity and interest into the club was allowing them to choose the main topic. The majority of the students voted on "Improving the Lives of Animals in Our Community." When asked the question in the preinterview, "How do you feel when you read an informational text at school (e.g, true facts about animals)?" many students lit up with excitement and replied things like, “...I love animals like snakes" (Dylan). "I just wanna know more and more about animals cause I know there's so much interesting stuff I don't even know. There's so much stuff I never knew about animals" (Steve). "I love animals, especially dogs and cats!" (Evan).

Along with allowing the students to choose their own topic, we also gave them the freedom of researching specific questions they were interested in while we supervised to ensure they stayed on track. They used iPads (iPad Mini 2, Apple, Inc., Cupertino, CA) to research their questions in small groups. For example, some questions they posed were, "How much trash is there in the United States? How much trash is there in the oceans?" Many of the students found short videos to watch or articles with pictures to read. In the journals we provided, the students wrote down the questions they were interested in and the answers they found by researching them (Figure 2). Levi asked the question, "Why do so many people litter?" recording that 250 million people litter. He responded, "Woah a lot and lots!" Cheyenne asked, "How much water do we get from the ocean?" and found that the ocean has 326 million mi. ${ }^{3}$ of water. 


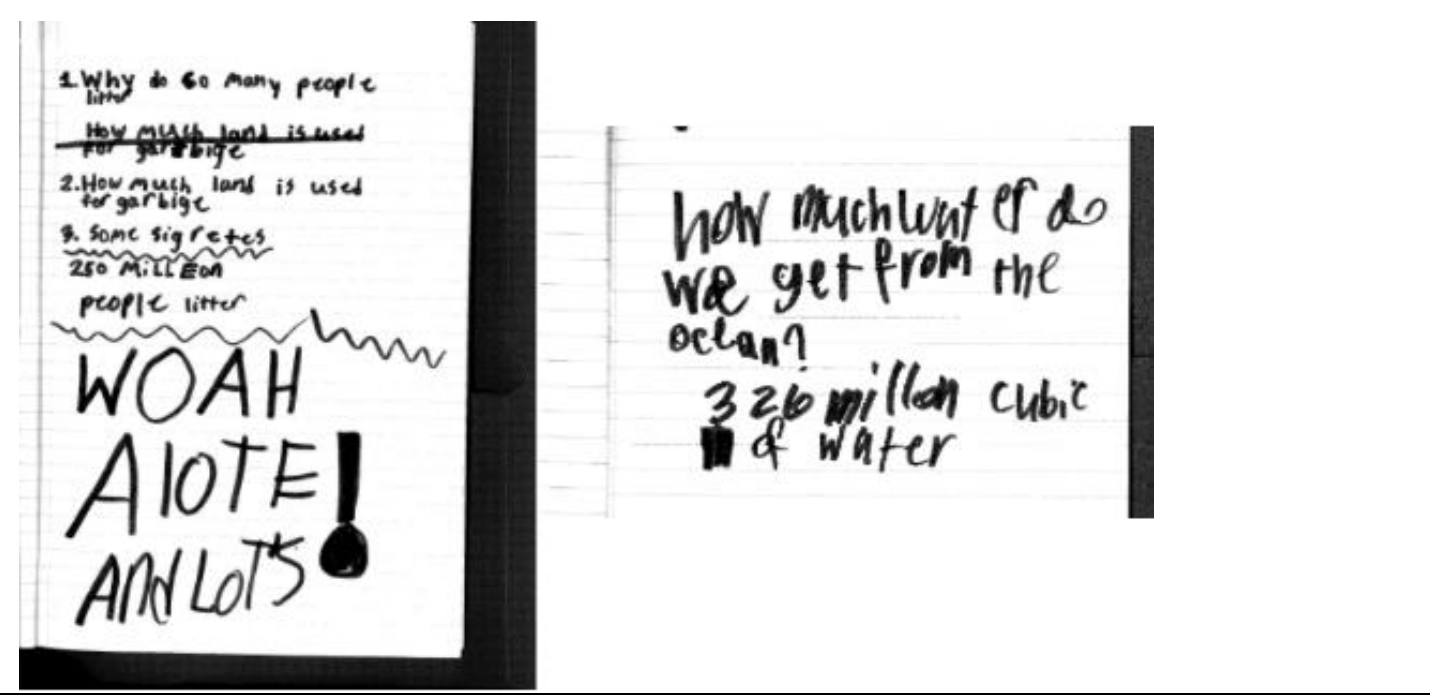

Figure 2. (Left) Levi's and (Right) Cheyenne's Project Journals

Prior to each meeting, we reviewed literature, web-based resources, and created guiding questions for discussions to give the students background information on what project or activity we would be doing that week. For example, before the meeting in which we focused on trash and recycling, we brought a book to read to the class called One Plastic Bag: Isatou Ceesay and the Recycling Women of the Gambia (Paul \& Zunon, 2015), along with an actual purse made from plastic bags like in the book. At the end of the meeting that day, we asked the students to write in their journals what they would do that week to minimize waste. Jazz wrote, "To help minimize waste this week, I will... I yose [use] my placestik [plastic] wardbodl [waterbottle]" (Figure 3).

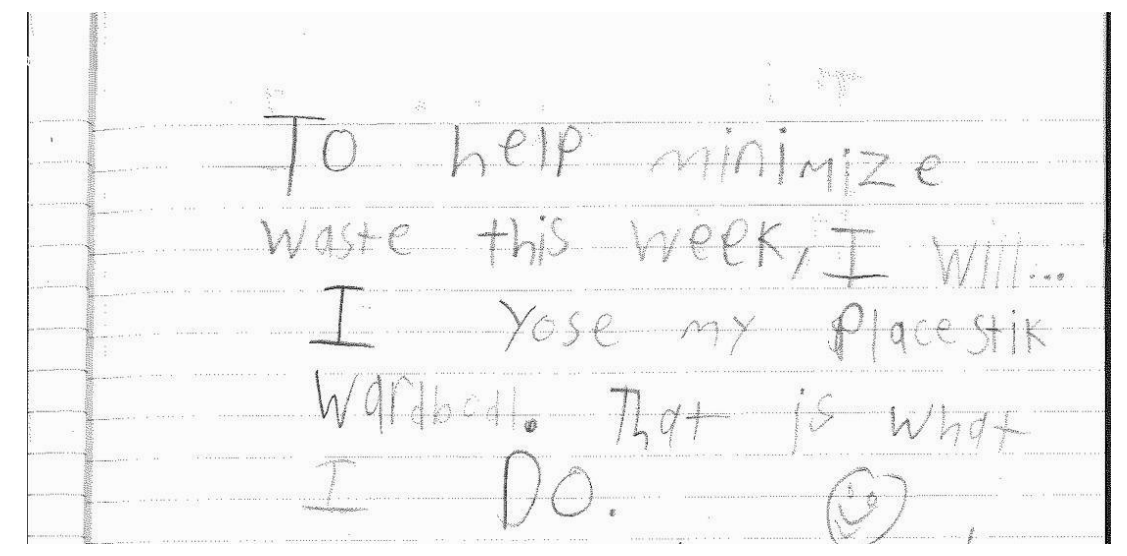

Figure 3. Jazz's Plan to Minimize Waste During the Week

During Week 6, the children's inquiry focused on water and the impact of trash and plastics, particularly on the oceans. The children brainstormed questions they wanted to answer, such as "Where do sewers go?" and "Which animals die because of plastic in the ocean?" (see Figure 4), then researched the questions on the iPads and recorded their findings in their journals. 


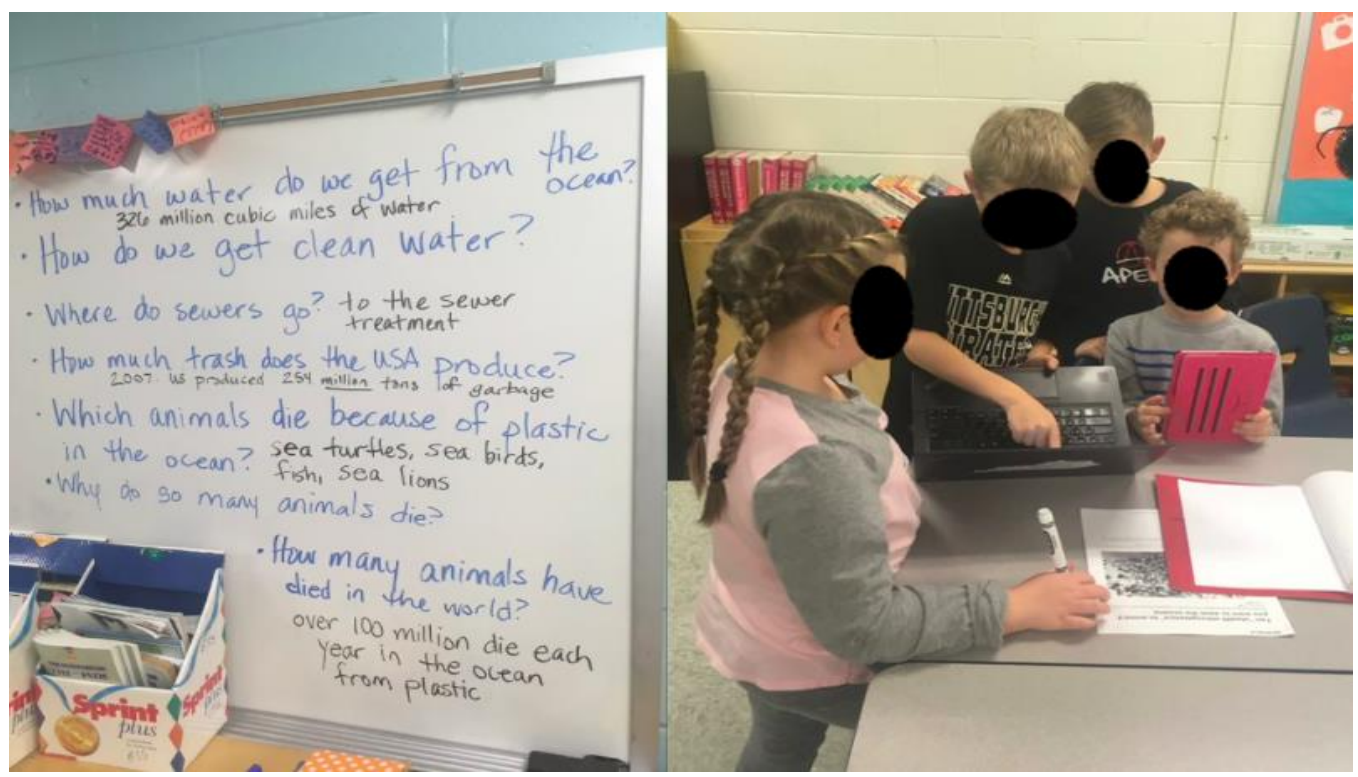

Figure 4. Student-Generated Questions (Left) and Students Using Laptops and Tablets to Research Their Questions (Right)

One interesting finding related to student-driven inquiry from this activity was the tension between the children's deep engagement in their research and the afterschool program staff members' expectations for behavior. The children were excited about their research, and they frequently jumped up and gathered together to share interesting findings (see Figure 4), or they shouted out their discoveries to be included with the questions listed on the board. While we viewed these behaviors as clear evidence of engagement in their work, the afterschool staff members appeared to view these behaviors as disruptive and problematic; they frequently urged children to go back to their seats, be quiet, and do their own work.

\section{Meaningful Tasks and Community Connections}

The first project the students completed was building bird feeders out of recycled materials. The students used the iPads to look up ideas for designing their bird houses and drew pictures of their plans in their journals. Weston drew a plan of using a milk jug as the bird feeder and cutting a hole in it to put the bird seed (Figure 5). Alexis drew multiple ideas for birdhouses using a tuna can, egg carton, and milk jug (Figure 5). The following week we brought in recycled materials (egg cartons, milk cartons, snack containers, etc.) and the students created their birdhouses out of the available materials (Figure 6). We gave them bird seed to put inside the feeders and asked them to draw in their journals where they planned to hang their feeders. At the following meeting, we asked if their feeders were successful, and many students told us where they hung them and if they saw birds eating out of them or not. 


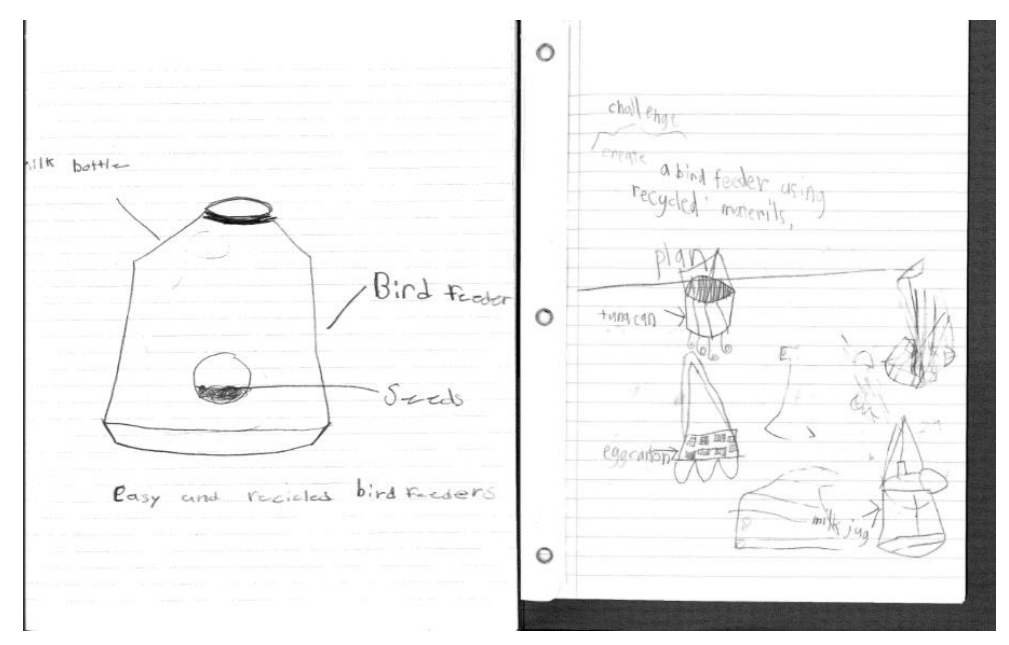

Figure 5. Weston's Drawing of His Plan to Use a Milk Jug for His Bird Feeder (Left); Alexis's Drawing of Her Plan to Use an Egg Carton, Tuna Can, or Milk Jug for Her Bird Feeder (Right)

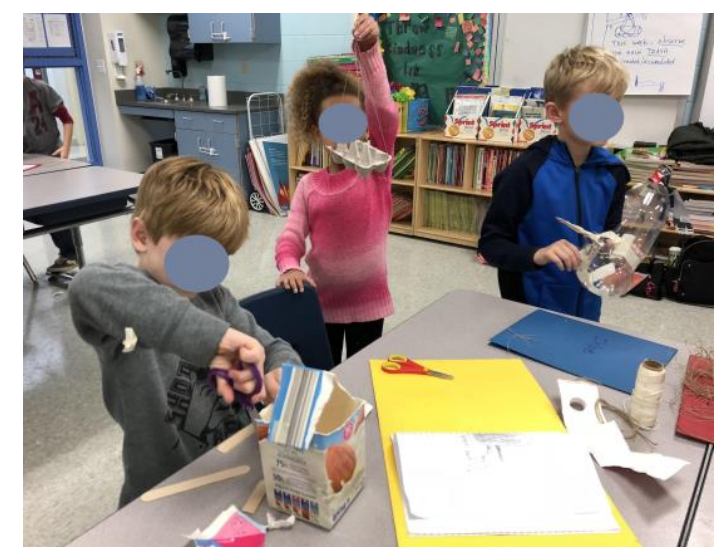

Figure 6. Students Creating Their Bird Feeders Out of Recycled Materials

To create another community connection, we invited guest speakers from the Environmental Youth Outreach student organization from our university. Two university students came and brought chocolate chip cookies as a mining activity for students to pick away at with toothpicks (Figure 7). However, an adjustment had to be made for students to use vanilla wafer cookies due to a food allergy. This made the example less effective because they did not have chocolate chips to mine, but the students still grasped the concept that the more damage done to an environment, the greater impact they will have on the depletion of natural resources. The guest speakers also discussed pollution and waste, then had metal straws they brought as gifts to remind students to reduce plastic waste by reusing their metal straws and water bottles. 


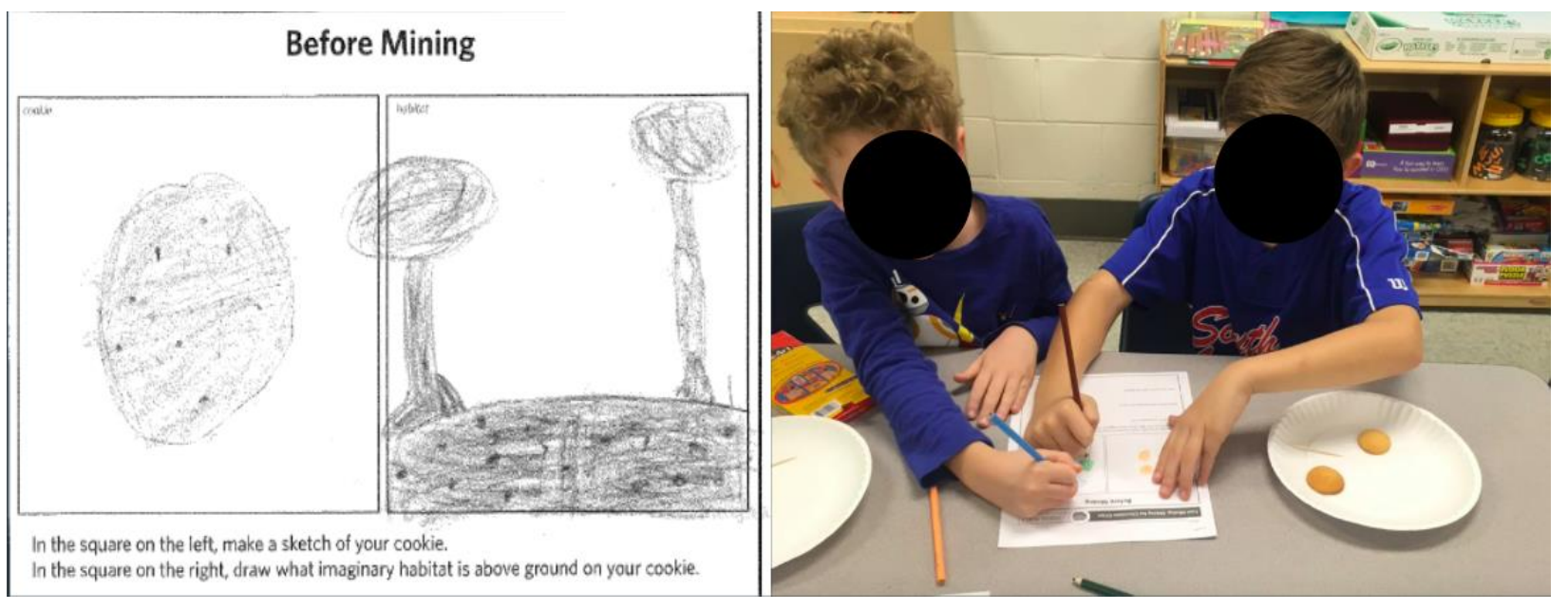

Figure 7. Students Collaborate on the Cookie-Mining Activity

During our last club meeting, students had the opportunity to write postcards to various stakeholders to encourage them to take environmental action. Together, we brainstormed different potential recipients, such as the local mayor-elect, the state Senate's environmental committee, the school district's liaison to the Sustainability Council for Youth, the school's principal, and the U.S. president. We talked about matching advocacy of various causes to recipients, such as requesting that the mayor increase local recycling options or that the president support funding for national parks. Using provided sentence frames as models, the children drafted the text of their postcards on a sticky note prior to filling in their postcards (Figure 8). The results of this activity clearly illustrated the power of engaging the children in meaningful activities with a clear community connection; we required the children to write one postcard, but nearly every child voluntarily wrote two to three postcards.
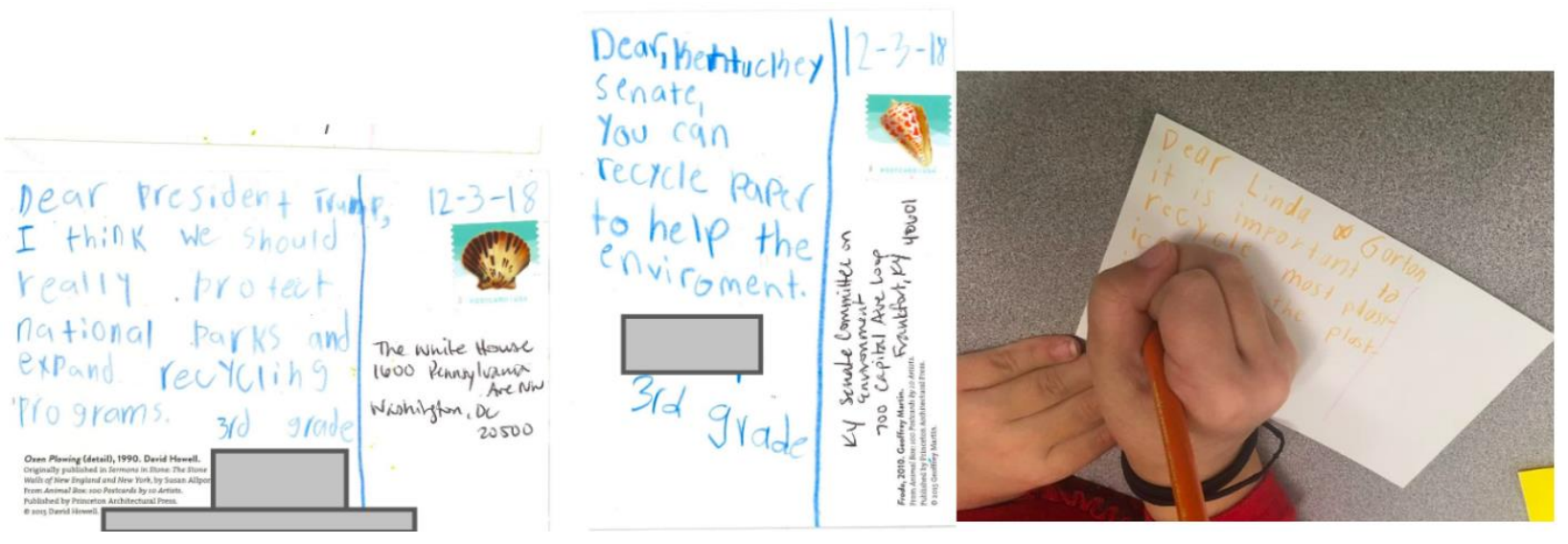

Figure 8. The Students Wrote Postcards to a Government Official (or Other Community Member) of Their Choice 


\section{Positive Attitudes}

Our third research question was investigated by using the pre- and postinterview questions and analyzing the student profiles we created. We were able to compare the overall results from the preinterviews vs. the postinterviews, and also the individual results of preinterviews vs.

postinterviews for each student.

Comparing the average responses of each presurvey question to each postsurvey question, we see an overall increase in positive attitudes towards math, literacy, and improving the community, as shown in Figure 9. Scores ranged from 1 (very sad face, least favorable) to 4 (very happy face, most favorable). Questions 1-2 were about math, Questions 3-4 were about literacy, and Questions 5-7 asked whether kids can make a difference by fixing issues in the community. Question 1 ("Do you think you are good at math?") had the highest increase of exactly 1 from pre- to postsurvey. The question that had the highest average pre-survey response (3.8), "Do you think you can use reading to help fix issues in the community?" was also the only question to show a decrease from pre- to postsurvey. This was likely due to a ceiling effect of it already being very high at the onset. Overall, we are cautiously optimistic in the potential for such afterschool experiences to have a positive influence on students' attitudes toward mathematics, literacy, and connections to the community.

\begin{tabular}{|c|l|}
\hline \multicolumn{2}{|c|}{ Questions } \\
\hline 1 & Do you think you're good at math? \\
\hline 2 & How do you feel when you do math? \\
\hline 3 & $\begin{array}{l}\text { Do you think you're good at reading? } \\
\text { How do you feel when you read } \\
\text { stories? }\end{array}$ \\
\hline 5 & $\begin{array}{l}\text { How do you feel about kids helping to } \\
\text { fix issues in their community? }\end{array}$ \\
\hline 6 & $\begin{array}{l}\text { Do you think you can use math to } \\
\text { help fix issues in your community? }\end{array}$ \\
\hline 7 & $\begin{array}{l}\text { Do you think you can use reading to } \\
\text { help fix issues in your community? }\end{array}$ \\
\hline
\end{tabular}

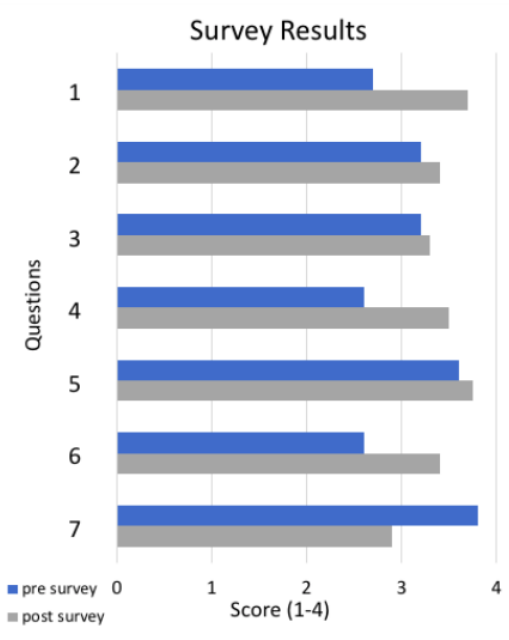

Figure 9. Parallel Questions From Pre-and Postsurveys That Were Used for Comparisons (Left). Graph of Pre-Versus Postsurvey Averages for Each Question (Right)

\section{Discussion and Implications}

The results of our project offer important implications for implementing PBL approaches to integrate mathematics, literacy, and community-based education. Creating more informal community-based experiences, such as taking field trips, would provide more opportunities for students to connect what they are learning to the real world. Simic-Muller et al. (2009) highly recommended using field trips as a way to show students how members of their community use math. With subjects as young as 7-9 years old, making math and literacy connections more explicit throughout the project might allow them to identify these connections more easily as integrated with broad environmental science 
topics. In the future, demonstrating to students that math can mean more than just simple addition and subtraction equations could help them identify these applications throughout the study. It would also be beneficial to have additional time (i.e. longer/more frequent meetings or longer timeframe of club). This would allow for more activities to be completed and more time for discussion of the activities.

The obvious disconnect between our expectations for the children's behavior and those of the afterschool program staff also point to another important implication from this study. PBL approaches draw upon children's intrinsic curiosity and interest, and they also require interaction and collaboration among learners. As a result, classroom management in a PBL context may look very different from more traditional environments, where children are expected to sit quietly, listen attentively to the teacher, and work independently. In addition to the support they receive for inquiry-based instructional practices, educators implementing PBL approaches for the first time may need professional development or coaching to help them work through a classroom management situation that may feel very foreign. Active bodies and loud voices are a natural part of a PBLoriented classroom, and teachers may need support to understand when these behaviors indicate deep engagement with inquiry as opposed to disruptive or off-task behavior. Educators who provide PBL in afterschool settings may need to explicitly work with program staff-who are often not trained educators - to help them understand differences between PBL and traditional instruction, including different approaches to classroom management.

One of the main limitations that we faced during the research was the grade level of the students. It is important to introduce real world applications of math and literacy along with civic engagement as early as possible; however, for research purposes, it is more difficult to collect interview data and journal entries from this age group. Because they are still developing their foundational math and literacy skills in second and third grade, many students struggled to be descriptive in their interview responses and journal entries. Attendance was another obstacle that we faced. Because the club took place in the afterschool program of an elementary school, the same students were not always in attendance, and if they were, they were sometimes picked up early. Therefore, some students likely missed out on crucial connections with math and literacy. Lastly, our club meetings only lasted one hour, so we were sometimes rushed during activities. If we had more time to slow down and discuss what we were doing with the students, they may have made more connections with the activities to math and literacy.

\section{References}

Basche, A., Genareo, V., Leshem, A., Kissell, A., \& Pauley, J. (2016). Engaging middle school students through locally focused environmental science project-based learning. Natural Sciences Education, 45, 1-10. doi:10.4195/nse2016.05.0012

Bell, S. (2010). Project-based learning for the 21st century: Skills for the future. Clearing House, 83, 39. doi:10.1080/00098650903505415

Capraro, K. (2017). "Making change" in second grade: Exploring money through project-based learning. YC Young Children, 72, 30-36.

Christensen, C. A. (2015). Community-engaged teaching: A project-based model. Teaching Artist Journal, 13, 14-27.

Edelsky, C. (1991). With literacy and justice for all: Rethinking the social in language and education. Bristol, PA: Falmer Press, Taylor \& Francis.

Genc, M. (2015). The project-based learning approach in environmental education. International Research in Geographical \& Environmental Education, 24, 105-117. doi:10.1080/10382046.2014.993169 
Hansen, M., Levesque, E., Valant, J., \& Quintero, D. (2018, June). The 2018 Brown Center report on American education: How well are American students learning? Washington, DC: Brown Center on Education Policy at the Brookings Institution.

Kawashima-Ginsberg, K. (2016). The future of civic education. Available at www.nasbe.org/wpcontent/uploads/Future-of-Civic-Education_September-2016-Standard.pdf

Krajcik, J. S., \& Blumenfeld, P. C. (2006). Project-based learning. In R. K. Saywer (Ed.), The Cambridge handbook of the learning sciences (pp. 317-334). Cambridge, United Kingdom: Cambridge University Press.

National Council for the Social Studies. (2013). Social studies for the next generation: Purposes, practices, and implications of the college, career, and civic life (C3) framework for social studies state standards (NCSS Bulletin 113). Silver Spring, MD: Author.

Paul, M., \& Zunon, E. (2015). One plastic bag: Isatou Ceesay and the recycling women of the Gambia. Minneapolis, MN: Millbrook Press.

Powell, R., Cantrell, S. C., \& Adams, S. (2001). Saving black mountain: The promise of critical literacy in a multicultural democracy. The Reading Teacher, 54, 772-778. Retrieved from http://www.jstor.org/stable/20204992

Rahm, J., Martel-Reny, M., \& Moore, J. (2005). The role of afterschool and community science programs in the lives of urban youth. School Science and Mathematics, 105, 283-291.

Simic-Muller, K., Turner, E. E., \& Varley, M. C. (2009). Math club problem posing. Teaching Children Mathematics, 16, 206-212.

Turner, E. E., Gutiérrez, M. V., Simic-Muller, K., \& Díez-Palomar, J. (2009). "Everything is math in the whole world": Integrating critical and community knowledge in authentic mathematical investigations with elementary Latina/o students. Mathematical Thinking and Learning, 11, $136-157$.

Westheimer, J. (2015). What kind of citizen? Educating our children for the common good. New York, NY: Teachers College Press.

Wilhelm, J., \& Confrey, J. (2005). Designing project-enhanced environments. The Science Teacher, 72,42 .

The Journal of Educational Research and Practice provides a forum for studies and dialogue that allows readers to better develop social change in the field of education and learning. Journal content may focus on educational issues of all ages and in all settings. It also presents peer-reviewed commentaries, book reviews, interviews of prominent individuals, and additional content. The objectives: We publish research and related content that examines current relevant educational issues and processes aimed at presenting readers with knowledge and showing how that knowledge can be used to impact social change in educational or learning environments. Additional content provides an opportunity for scholarly and professional dialogue regarding that content's usefulness in expanding the body of scholarly knowledge and increasing readers' effectiveness as educators. The journal also focuses on facilitating the activities of both researcher-practitioners and practitioner-researchers, providing optimal opportunities for interdisciplinary and collaborative thought through blogging and other communications. Walden University Publishing:

http://www.publishing.waldenu.edu 